Original scientific paper

UDC: 639.11

DOI: $10.15679 /$ bjwr.v4i1.31

\title{
FIRST OCCURENCE OF Thelazia callipaeda IN FOXES (Vulpes vulpes L.) IN SERBIA
}

\author{
Pavlović I. ${ }^{1}$, Jakić-Dimić D. ${ }^{1}$, Kureljušić B. ${ }^{1}$, Ćirović $D{ }^{2}{ }^{2}$, Jezdimirović ${ }^{1}{ }^{1}$, Drobnjak M. ${ }^{3}$
}

Summary: Thelazia callipaeda is a vector-borne zoonotic eye worm, parasitizing at the conjunctiva sac of domestic and wild carnivores (dogs, cats, foxes, and wolves), and humans. Over the last decade, infection with that spirudida is increasingly occurring in dogs and cats in the numerous European countries including the Balkans area. In Serbia we also established infection with this parasites in foxes during 2014. Adult nematodes were retrieved from the conjunctival sacs of 3 animals ( 2 from Belgrade area and 1 from Braničevo district) hunted during control effect of oral vaccination of foxes against rabies. In total we extracted 23 parasites, 10 males and 13 females. This is the first report of autochthonous cases of T. callipaeda infection in red foxes in Serbia.

Keywords: foxes, Serbia, Thelazia callipaeda

\section{Introduction}

Thelazia callipaeda (Spirurida, Thelaziidae), is a nematode parasite that lives in the conjunctival sac of domestic and wild carnivores and humans (Rossi and Bertaglia,1989; Anderson,2000; Otranto and Dantas-Torres,2013). Parasites are also known as the "oriental eye worm" due to its geographical distribution in the former Soviet Republics and in many far eastern countries (Otranto and Dantas- Torres,2015). Infection cause the adult and larval stages (Anderson,2000) In the infected hosts, the presence of worms may induce different degrees of clinical signs, ranging from mild (e.g., conjunctivitis, epiphora, and ocular discharge) to severe (e.g., keratitis, and corneal ulcers and blindness) ocular disease. Over the last decade, infection with that parasites is increasingly occurring in dogs and cats in the numerous European countries (e.g., Italy, France, Germany, Switzerland, Spain, Portugal) (Rossi and Bertaglia,1989; Lia et al.,2000; Otranto et al.,2003a; Dorchies et al.,2007; Miró et al.,2011; Rodrigues et al.,2012). During last few years infection are established in the Balkans countries too (Serbia, Romania, Croatia, Bosnia and Herzegovina) (Hodžić et al.,2014; Mihalca et al.,2015). The first autochthonous cases of dogs and cats infection by T. callipaeda in Serbia established during 2012 (Gajić et al.,2014). At same time, we had report about its occurrence on foxes in Italy Switzerland and Bosnia and Herzegovina (Otranto et al.,2003a,2009; Malacrida et al.,2008; Hodžić et al.,2014). In Serbia we also established infection with thelazia in foxes and in this paper we reported first cases of autochthonous fox's thelaziosis on different localities in Serbia.

\footnotetext{
${ }^{1}$ Ivan Pavlović, PhD, Research Fellow; Dobrila Jakić-Dimić, PhD; Research Fellow; Branislav Kureljušič, PhD, Research Associate; Nemanja Jezdimirović, DVM, Research Assistant; Scientific Veterinary Institute of Serbia, V.Toze 14, 11000

${ }^{2}$ Duško Ćirović, PhD, professor, Faculty of Biology, University of Belgrade, Studentski trg 16, 11000 Belgrade, Serbia.

${ }^{3}$ Marija Drobnjak, DVM,Veterinary Ambulance PetVetCare, V.Gaćinovića 2, 11000 Belgrade, Serbia. 


\section{Material and Methods}

Throughout the realisation of the Project Fiche - IPA centrallised programmes for the Control/Eradication and Classical Swine Fever and Rabies in Republic of Serba, in period 20122014 were submitted the heads of hunted foxes to the review to determine the effect of oralne vaccination. During 2014, while opservation of heads of foxes, we established presence of adult nematodes from the conjunctival sacs of 3 animals (2 from Belgrade area and 1 from Braničevo district - Požarevac). The collected nematodes were fixed in glacial acetic acid and preserved in $70 \%$ ethanol. For further examination, parasites were cleared in lactophenol and nematodes were identified by its morphometric characteristics described by Skrjabin et al. (1967). Determinate of parasites measurement were performed by ocular micrometers. We measured body length and maximal width of adult parasites, number and position of postcloacal papillae and spicule length in males, as well as the position of the vulva in females. The numbers and measure of pre-cloacal and postcloacal papillae in males differ among species. Also, the location of the vaginal opening and the number of cuticular transverse striations differ among species and use to identification a thelazia species.

\section{Results And Discussion} 1).

During our examination we collected 23 samples of T. Callipaeda - 10 males and 13 females (Table

Table 1. Occurrence of T.callipaeda at foxes in Serbia

\begin{tabular}{|l|l|c|c|c|}
\hline No & Locality & \multirow{2}{*}{ Parasite location } & \multicolumn{2}{|c|}{ Number of parasites } \\
\cline { 4 - 5 } & & & total & $* \mathrm{~m} / \mathrm{f}$ \\
\hline 1 & Belgrade & left eye & 7 & $2 / 5$ \\
\hline 2 & Belgrade & left eye & 11 & $4 / 7$ \\
\hline 3 & Požarevac & left eye & 5 & $1 / 4$ \\
\hline
\end{tabular}

All parasites located in left eye of foxes (Figure 1).

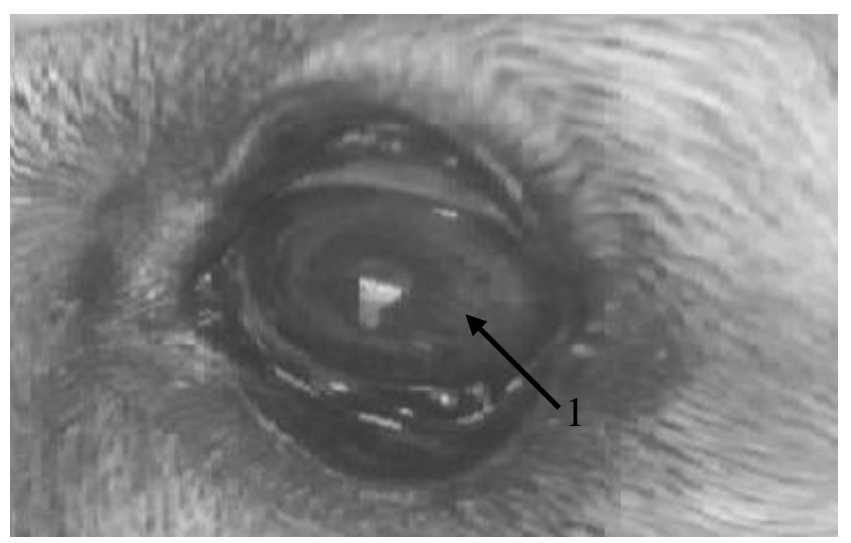

Figure 1. Thelazia callipaeda in fox eye 
Worms are creamy white with non-segmented body and strong oral and anal part. In both, males and females, the corners of the mouth are without the lips and hexagonal consisting of two concentric rings of flattened papilla around a central aperture. They do not have sharp spines or hooks in the mouth or elsewhere on the body.

Male worms ranged from 10.21-13.46 mm in length, and 337-442 $\mu \mathrm{m}$ in width. All male worms had five pairs of postcloacal papillae on the ventral side of the body. The distance from the position of the cloaca to the end of the tail ranged from 71-83 $\mu \mathrm{m}$. Right spicule was shorter and length ranged from 142$155 \mu \mathrm{m}$. Left spicule was much longer length, ranged from 1.423-1.779 mm (Figure 2).

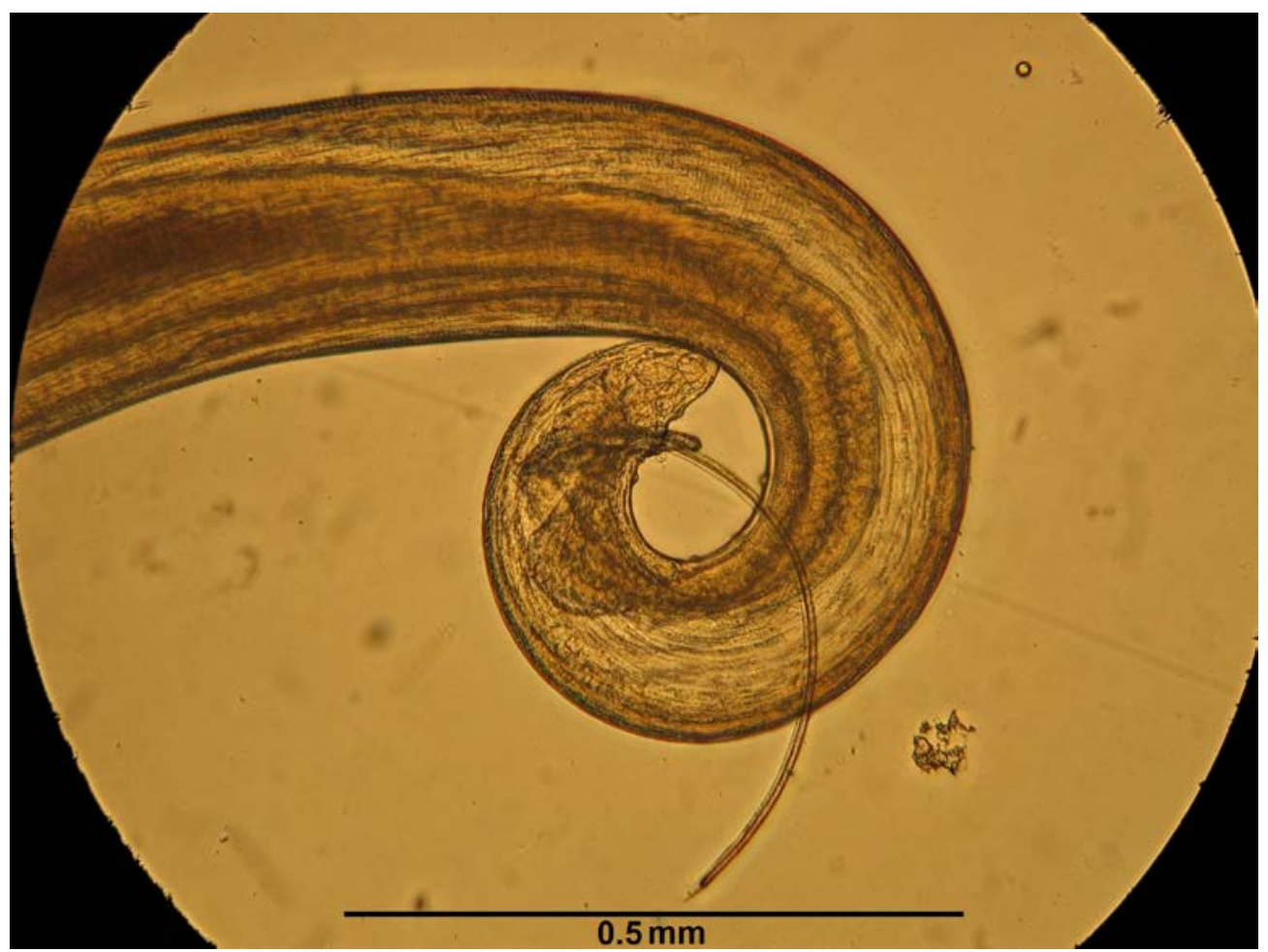

Figure 2. Male tale of Thelazia callipaeda

Female worms ranged from 14.51-17.45 mm in length, and 401-433 $\mu \mathrm{m}$ in width. At female worms vulva was situated anterior to the oesophago-intestinal junction and the distance between the vulva and buccal extremity ranged from 567-632 $\mu \mathrm{m}$ in length (Figure 3).

Thelazia callipaeda (Spirurida, Thelaziidae) is an arthropod-borne disease. The worms are viviparous, and the first-stage larvae are passed by females into the lachrymal secretions where they are ingested by nonbiting Diptera flies (Hong et al.,1988). Larval development takes place in the thorax and abdomen of the vector, and infective stages are present in 18-25 days. Development to the adult stage takes place without migration, and the prepatent period is between 3 and 6 weeks. The first stage larva of Thelazia is very shortlived in the lachrymal secretions, only surviving a few hours, and transmission depends upon the continuous presence of the vectors. For this reason, thelaziasis has a seasonal occurrence according to the seasonality of the intermediate hosts The expansion of this nematode is related to the occurrence of its vector, Phortica variegata (Drosophilidae, Steganinae), which is a lachrymophagous fly with a zoophilic behaviour (Otranto et al.,2005,2006). These flies buzz around the eyes of animals and humans at the daytime, finally landing on the eyes and releasing the infective larvae on the host conjunctiva (Otranto and Dantas-Torres,2015). 


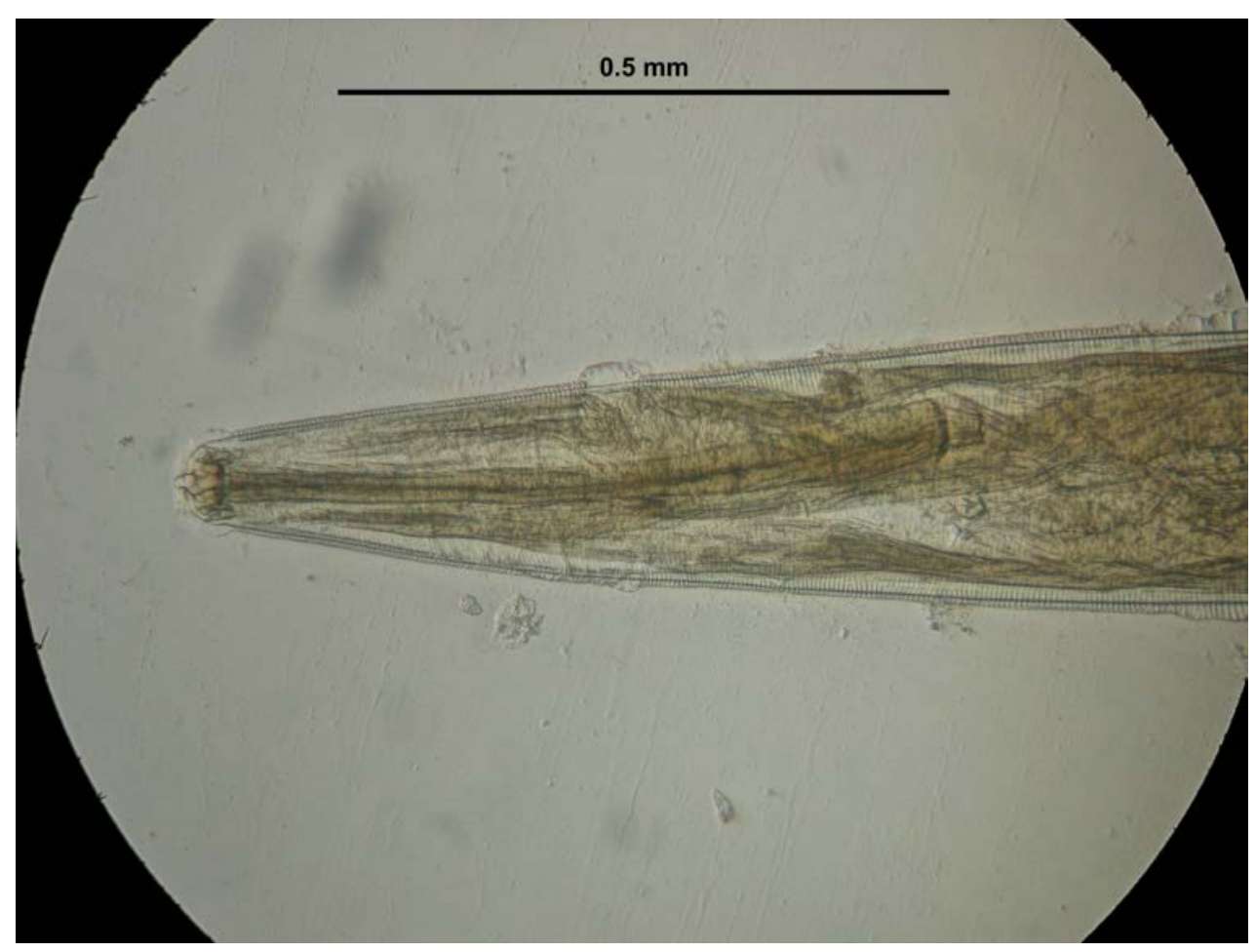

Figure 3. Female Thelazia callipaeda

For this reason, thelaziasis has a seasonal occurrence according to the seasonality of the intermediate hosts The expansion of this nematode is related to the occurrence of its vector, Phortica variegata (Drosophilidae, Steganinae), which is a lachrymophagous fly with a zoophilic behaviour (Otranto et al.,2005,2006). These flies buzz around the eyes of animals and humans at the daytime, finally landing on the eyes and releasing the infective larvae on the host conjunctiva (Otranto and Dantas-Torres,2015). Under natural conditions only males of P.variegata were found to be infected with T. callipaeda, whereas both male and female flies were positive in dissection and/or molecular assays under experimental conditions (Otranto et al. 2003b,c, 2006). The climate of the countries in which T. callipaeda has been reported varies from tropical and subtropical in the Far East, to temperate in the Russian Federation and Europe. In a study which was carried out in Italy confirm the hypothesis that the vectors of T. callipaeda need a mountainous environment for their survival and biological cycle, and the high prevalence in dogs and foxes indicates that T. callipaeda infection is hyper-endemic in this area (Otranto et al.,2003b). This was confirmed by our research that the presence of the T. callipaeda found in foxes hunting in the mountainous area of Serbia and that infected foxes, dogs and cats originated from the same regions (Gajić et al.,2014).

\section{Conclusion}

Our results are the first report of autochthonous cases of $\mathrm{T}$. callipaeda infection in red foxes in Serbia and present important epidemiological data about spread of thelazia in Serbia

\section{References}

1. Anderson, R.C. (2000). Nematode Parasites of Vertebrates: Their Development and Transmission. CABI Publishing, Guilford. 
2. Dorchies, P., Chaudieu, G., Siméon, L.A., Cazalot, G., Cantacessi, C., Otranto, D. (2007) First reports of autochthonous eyeworm infection by Thelazia callipaeda (Spirurida, Thelaziidae) in dogs and cat from France. Veterinar Parasitology, 149, pp. 294-297.

3. Gajić, B., Bogunović, D., Stevanović, J., Kulišić, Z., Simeunović, P., Stanimirović, Z. (2014) Canine and feline thelaziosis caused by Thelazia callipaeda in Serbia. Acta Veterinaria-Beograd, 64(4), pp. 447-455.

4. Hodžić A, Latrofa MS, Annoscia G, Alić A, Beck R, Lia RP, Dantas-Torres F, Otranto D. (2014) The spread of zoonotic Thelazia callipaeda in the Balkan area. Parasites \& Vectors, 7, pp.352-357.

5. Hong, ST., Lee, S.H., Kim, S,I. (1988) A human case of Thelazia callipaeda infection with reference to its internal structures. Korean Journal of Parasitology, 26, pp.137-139,

6. Lia, R.P., Garaguso, M., Otranto, D., Puccini, V. (2000) First report of Thelazia callipaeda in Southern Italy, Basilicata region. Acta Parasitologica, 45, pp.178-181.

7. Malacrida, F., Hegglin, D., Bacciarini, L., Otranto, D., Nägeli, F., Nägeli, C., Bernasconi, C., Scheu, U., Balli, A., Marenco, M., Togni, L., Deplazes, P., Schnyder, M. (2008) Emergence of canine ocular thelaziosis caused by Thelazia callipaeda in southern Switzerland. Veterinary Parasitology, 157, pp.321-327.

8. Mihalca, A.D., D’Amico, G., Scurtu, I., Chirilă, R., Matei, I.A., Ionică, A.M. (2015) Further spreading of canine oriental eyeworm in Europe: first report of Thelazia callipaeda in Romania. Parasites \& Vectors,8, pp. 48 doi:10.1186/s13071-015-0663-2

9. Miró, G., Montoya, A., Hernández, L., Dado, D., Vázquez, M.V., Benito, M., Villagrasa, M., Brianti, E., Otranto, D. (2011) Thelazia callipaeda: infection in dogs: a new parasite for Spain. Parasites \& Vectors,4, pp.148-152

10. Otranto, D., Ferroglio, E., Lia, R.P., Traversa, D., Rossi, L. (2003a) Current status and epidemiological observation of Thelazia callipaeda (Spirurida, Thelaziidae) in dogs, cats and foxes in Italy: a "coincidence“ or a parasitic disease of the Old Continent? Veterinary Parasitology, 116, pp.315-325.

11. Otranto, D., Tarsitano, E.; Traversa, D., De Luca, F.; Giangaspero, A. (2003b). Molecular epidemiological survey on the vectors of Thelazia gulosa, Thelazia rhodesi and Thelazia skrjabini (Spirurida: Thelaziidae). Parasitology,127, pp.4-7.

12. Otranto, D., Lia, R.P,, Cantacessi, C., Testini, G., Troccoli A., Shen, J.L., Wang, Z.X. (2005) Nematode biology and larval development of Thelazia callipaeda (Spirurida, Thelaziidae) in the drosophilid intermediate host in Europe and China. Parasitology,131, pp.847-855.

13. Otranto, D, Cantacessi, C, Testini, G, Lia, R.P. (2006) Phortica variegata as an intermediate host of Thelazia callipaeda under natural conditions: evidence for pathogen transmission by a male arthropod vector. International Journal of Parasitology, 36, pp.1167-1173.

14. Otranto, D., Dantas-Torres, F., Mallia, E., Digeronimo, P.M., Brianti, E., Testini, G.,Traversa, D,, Lia, R.P. (2009) Thelazia callipaeda (Spirurida, Thelaziidae) in wild animals: Report of new host species and ecological implications. Veterinary Parasitology, 166, pp.262-267.

15. Otranto, D., Dantas-Torres, F., Brianti, E., Traversa, D., Petrić, D., Genchi, C., Capelli, G. (2013) Vector-borne helminths of dogs and humans in Europe. Parasites \& Vectors, 6, pp.16-19

16. Otranto, D., Dantas-Torres, F. (2015 Transmission of the eyeworm Thelazia callipaeda:between fantasy and reality. Parasites \& Vectors, 8, pp.273-275

17. Rodrigues, F.T., Cardoso, L., Coutinho, T., Otranto, D,, Diz-Lopes, D. (2012) Ocular thelaziosis due to Thelazia callipaeda in a cat from northeastern Portugal. Journal of Feline Medical Surgery 14, pp. 952-954

18. Rossi, L., Bertaglia, P. (1989) Presence of Thelazia callipaeda Railliet and Henry, 1910, in Piedmont, Italy. Parassitologia, 31, pp.167-172.

19. Skrjabin, K.I., Sobolev, A.A., Ivashkin, V.M. (1967) Spirurata of animals and man and the diseasecaused by them. Part 4: Thelazioidea. In: Essential of Nematodology. Vol. XVI. Moscow,USSR: Academy of Sciences of the USSR.

Received: 21.01.2016.

Accepted: 14.06.2016.

Pavlović I., Jakić-Dimić D., Kureljušić B., Ćirović D., Jezdimirović N., Drobnjak M. (2017). First occurence of Thelazia Callipaeda in foxes (Vulpes Vulpes L.) in Serbia, Balkan Journal of Wildlife Research, 4(1), pp. 1-5. 